\title{
Preliminary Experience of Glove Single Port Laparoscopic Appendectomy in Children and Adolescents for Uncomplicated Appendicitis
}

\section{Yasser Ashour Mohamed", Mohamed Ahmed Negm ${ }^{2 *}$, Ibrahim Ahmed Gamaan ${ }^{1}$, Sayed Ahmed Elhady ${ }^{1}$ and Mohamed Mohamed Shahin ${ }^{1}$}

${ }^{1}$ Department of Pediatric Surgery, Al-Azhar University, Cairo, Egypt

${ }^{2}$ Pediatric Surgery Unit, Qena Faculty of Medicine, South Valley University, Qena, Egypt

*Corresponding Author: Mohamed Ahmed Negm, M.D, Pediatric Surgery Unit, Qena Faculty of Medicine, South Valley University, Qena, Egypt.

E-mail: drmohamednegm@yahoo.com

Official E-mail: drmohamednegm@med.svu.edu.eg

ORCID ID: https://orcid.org/0000-0003-0633-9147

DOI: $10.31080 /$ ASPE.2020.03.0226
Received: January 07, 2020;

Published: February 20, 2020

(C) All rights are reserved by Mohamed

Ahmed Negm., et al.

\begin{abstract}
Background: Laparoscopic appendectomy has been widely applied and became popular procedure for the surgical management of appendicitis. Glove single port laparoscopic appendectomy [GSPLA] is a new technical modification of single incision laparoscopic surgery [SILS]. By this approach the laparoscopic instruments introduced to the abdomen through a longitudinal one umbilical incision only.

Purpose: This study aimed to present two centres initial experiences using home-made glove single port for laparoscopic appendectomy [GSPLA] in children and adolescents.

Patients and Methods: This prospective study was conducted on patients of pediatric age with uncomplicated appendicitis using GSPLA. This was done through a 2 - $\mathrm{cm}$ trans-umbilical longitudinal incision. Then the inner flexible plastic ring (FPR) inside the out folded glove was inserted into the abdominal cavity using a curved artery forceps. The open end of the glove was passed through the rigid outer ring (ROR) where it was stretched and folded several times around the ROR for tightening over the anterior abdominal wall. The fingers of glove act as site for introduction of [laparoscopic instruments, ports and camera.

Results: Seventy-two children with acute uncomplicated appendicitis were surgically treated by GSPLA. Their mean age was $13 \pm 2.8$ years (ranged from 7-16 years). All procedures were completed laparoscopically without conversion. Only two cases were converted to multiport laparoscopic procedure. The operative time was ranged from $35-79$ (mean $=45.24 \pm 12.14$ min). Post- operative ileus was seen in 2 patients $(2.77 \%)$ and improved under conservative treatment. No report of umbilical infection or hernia after 6 months of follow up.

Conclusion: The GSPLA is a new procedure which is very cheap, easy to be done. In addition to high flexibility and wide range of movement of the instruments in comparison with the other single incision laparoscopic trocar (SILT) devices in the market.

Keywords: Glove Single Port; Endoscopic Appendectomy; Children; Laparoscopy; One Port Endosurgery
\end{abstract}

\section{Abbreviation}

AAP: Acute Appendicitis; CLA: Conventional Laparoscopic Appendectomy; FPR: Flexible Plastic Ring; LAP: Laparoscopic Appendectomy GSPLA: Glove Single Port Laparoscopic Appendectomy; ROR: Rigid Outer Ring; SILAP: Single Incision Laparoscopic Appendectomy; SILS: Single Incision Laparoscopic Surgery; SILT: Single Incision Laparoscopic Trocar.

\section{Introduction}

Appendectomy is a well-established surgical procedure for the treatment of appendicitis. The operation can be performed as an open surgery or by laparoscopy. A further development in the minimally invasive appendectomy technique has been the introduction of single incision laparoscopic appendectomy (SILAP) [1,2].
Laparoscopic appendectomy (LAP) P has been considered the best surgical choice for the treatment of appendicitis [3-5].

Esposito was the first to report the technique of SILAP in pediatric age. But it is still not a well-established technique and not widely practiced because it is ergonomically challenging when compared with multi-port laparoscopic procedure. Moreover, SILT access decreases the range of movement for the surgeon and assistant with lack of triangulation [6-8]. The commercially available SILT in addition to its high cost needs special instruments with limited range of movements especially when performed in children [9]. 
This study aimed to present the outcome of initial experience of SILAP using a home-made surgical glove for uncomplicated appendicitis in children and adolescents.

\section{Patients and Methods}

This prospective study included all children and adolescents with non-complicated appendicitis. The study was done in two pediatric surgery centres of Al-Azhar, Qena University Hospitals and affiliated hospitals during the period from October 2016 to January 2019. All children were subjected to laparoscopic appendectomy with GSPLA technique.

Pelvi-abdominal ultrasound was done by a senior radiologist for all patients.

\section{Ethical consideration}

The study was approved for clinical study by Ethical Research Committee. Before enrolment of the patients in this study, the parents were agreed and signed a written consent.

\section{Pre-operative preparations}

After history taking and thorough clinical evaluation, abdominal U/S, CBC, CRP and urine analysis were carried out. Antibiotic in the form of 3rd generation Cephalosporins (100 mg/kg BW) and Metronidazole $7.5 \mathrm{mg} / \mathrm{kg} \mathrm{BW/dose} \mathrm{were} \mathrm{given} \mathrm{to} \mathrm{all} \mathrm{cases.}$

\section{Operative techniques}

Anaesthesia

General with endotracheal intubation.

\section{Surgical technique}

Patient position: Supine with little tilting of the table to the left side and 30- degree Trendelenburg position. Before the skin drape, the umbilicus was cleaned thoroughly with alcohol swabs and Povidone Iodine solution which was applied also from the nipple to the mid-thigh.

The home-made surgical glove single port was prepared from FPR about 4-6 cm in diameter, a rigid outer ring (ROR) with a larger size and two surgical gloves No. 6.5. The fingers end of the glove was passed through the inner FPR and the open end turned around it in the middle of the glove so to become inside the out folded glove toward glove fingers (figure 1). After infiltration of local anaesthesia around the umbilicus, a longitudinal umbilical skin incision of about two $\mathrm{cm}$ was done and deepened to include the fascia and peritoneum. Then 4 stay sutures were inserted to the four corners of the fascia and peritoneum for traction during insertion of FPR inside the two layers of the glove (figure 2).

Insertion of the well lubricated inner FPR to the peritoneal cavity by using a curved artery forceps. The open end of the glove was passed through the outer ROR where it was stretched and turned several times around the ROR for tightening over the anterior abdominal wall (figure 3).

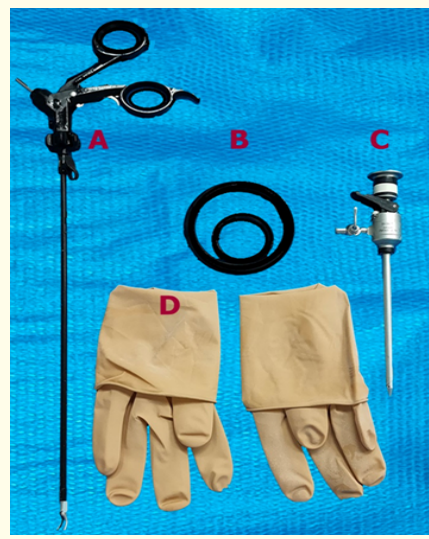

Figure 1: Materials and instruments used for construction of Home-Made Glove Single Port.

A) Laparoscopic conventional instrument. B) Elastic soft and rigid ring. C) Re-usable 5-mm. port. D) surgical glove.

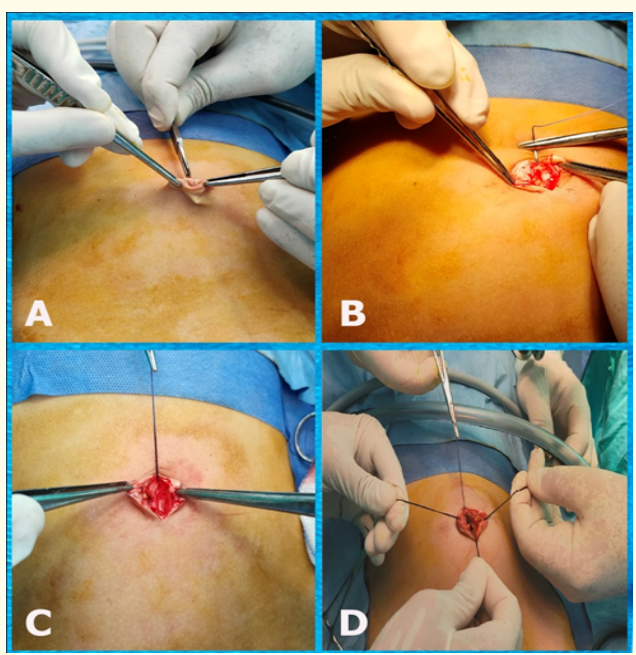

Figure 2: Steps of longitudinal umbilical incision and insertion of 4 stay sutures for traction and easy insertion of glove single port.

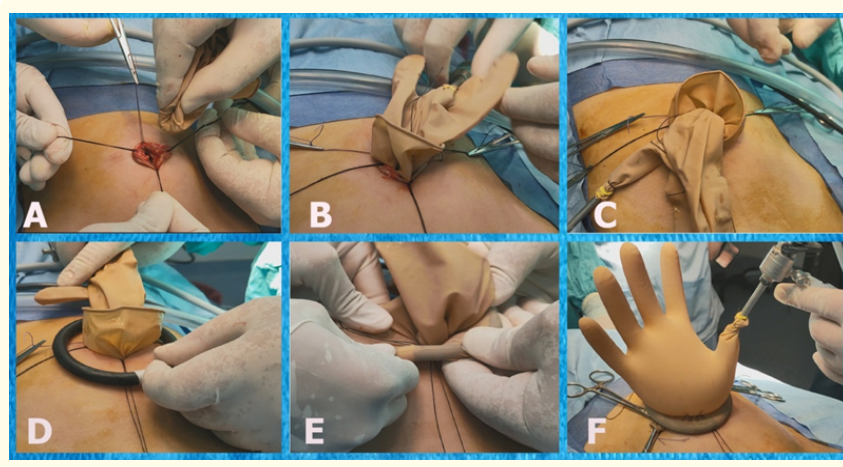

Figure 3: Insertion of home-made glove single port through umbilical incision.

A) Passing the inner ring through the umbilical incision aided by traction sutures. B) Insertion completed C) Insertion and fixation of the reusable working port. D) Application of rigid outer ring. E) Rolling of the glove over the outer ring. F) The glove single port with complete fixation to the abdominal wall through the inner and outer ring and inflation of abdomen. 
A 5-mm port was then passed inside the thumb and fixed with a piece of elastic rubber band from the tips of other glove to prevent dislodgement. This port was used for $\mathrm{CO} 2$ insufflation and passing the 5-mm scope into the peritoneal cavity (figure 4). Two conventional laparoscopic instruments [3-mm or 5-mm] were introduced in similar way as the scope into the fingertips of the glove without trocar (figure 4). After creation of pneumoperitoneum with pressure gradient from $8-12 \mathrm{mmHg}$ according to child's age, the peritoneal cavity was explored and the inflamed appendix was identified (figure 5). Then the whole peritoneal cavity was explored to exclude complicated appendicitis. The monopolar diathermy was used in heat coagulation of meso-appendix and in some cases Harmonic Scalpel was used. The base of the appendix was tied using extra corporeal Roader's knot. One of the unused fingers of the glove was used to exteriorise the appendix. Lastly closure of umbilical wound was done after gradual deflation of the peritoneal cavity (figure 6).

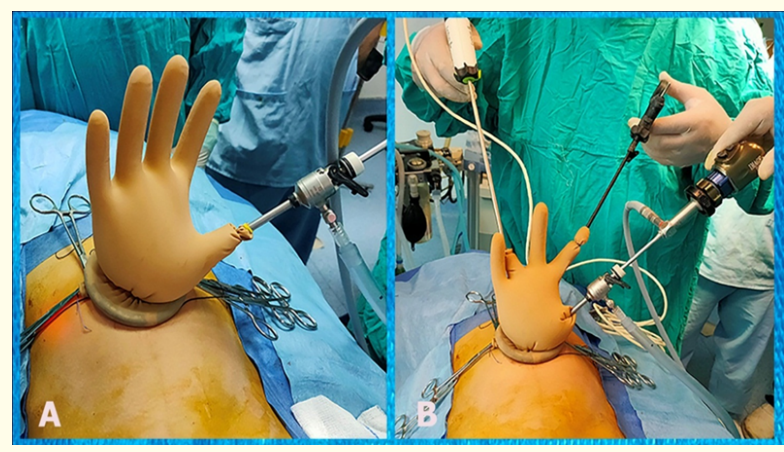

Figure 4: A) Camera port was introduced through the thumb finger of the glove with pneumoperitoneum. B) Position of the surgeon, camera man and the working instruments.

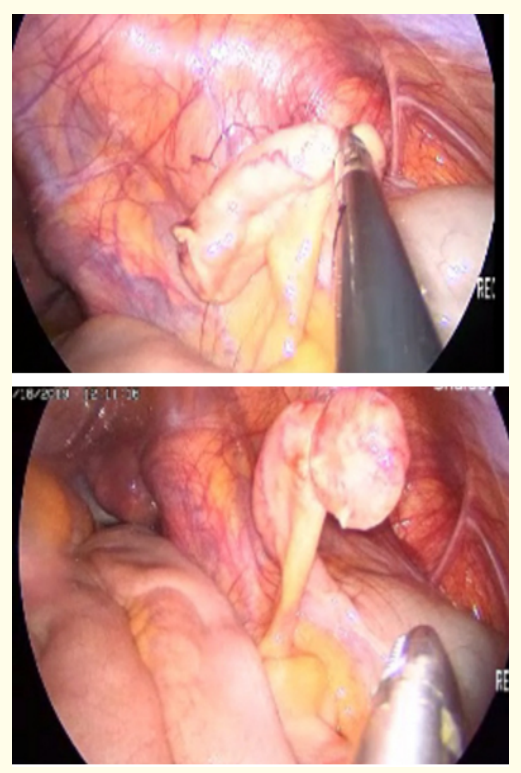

Figure 5: Intraoperative view of acute appendicitis

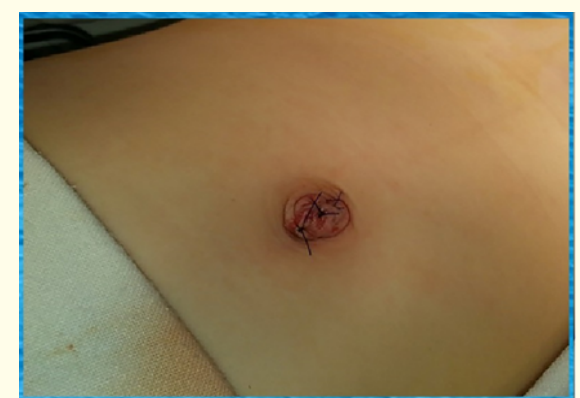

Figure 6: Immediate post- operative photo of umbilical wound

\section{Postoperative care}

Good hydration by IV fluid, continue antibiotics as previously described, and NSAID for analgesia. All children were allowed to take clear liquid diet after returning of normal intestinal sounds and the diet was advanced gradually as tolerated. Patients were discharged home when tolerating a regular diet, usually at the morning of the second post-operative day. However, some patients were discharged home in the evening of the operative day. For more details of the technique see the following link:

https://drive.google.com/open?id=1ildmUu-OGyx8jQcGoNLwvwLv-w-0jrd0

\section{Follow-up}

The patients were followed up at out -patient clinic weekly for the first month then monthly for 6 months.

\section{Statistical analysis}

Data were analysed using the statistical package for social sciences, version 24.0 (SPSS Inc., Chicago, Illinois, USA). Quantitative data were expressed as mean \pm standard deviation (SD). Qualitative data were expressed as frequency and percentage.

\section{Results}

Seventy-two children with AAP were included in this study. The demographic data of the patients is shown in Table 1. The appendix was accessible in 56 (77.8) cases and was challenging in [16 $(22.2 \%)]$ patients. However, the majority of cases were completed by GSPLA. Five cases (6.9\%) were converted to CLA due to retrocecal hidden appendix with difficult visualization of the appendix by GSPLA technique. Harmonic Scalpel was used to control the mesoappendix in $40(58.3 \%)$ cases and by diathermy in $30(41.7 \%)$ cases. The base of the appendix was controlled by extracorporeal knot in all patients. No cases needed conversion to open appendectomy. The operative time was ranged from 35 - 79 min. (Mean= $45.24 \pm 12.14 \mathrm{~min})$.

Postoperative ileus was seen in 2 patients $(2 / 72=2.77 \%)$ that improved conservatively. No other abdominal complications reported in this study. The mean postoperative hospital stay was $41.99 \pm 6.53$ hours. All patients were regularly attending the follow up for the first 3 visits and the majority were followed by telephone call only. No umbilical infection or hernia developed in the followup period which ranged from 2-6 months. 


\begin{tabular}{|l|c|c|}
\hline \multicolumn{1}{|c|}{ Procedure } & \multicolumn{2}{c|}{ GSPLA } \\
\hline No. of patients & $\mathrm{N}=72$ & $\%$ \\
\hline Sex & 50 & $69,44 \%$ \\
Male & 22 & 30.56 \\
Female & $12 \pm 1.6$ & \\
\hline Mean age in years & $7-16$ & \\
Range in years & 2 & $2.8 \%$ \\
\hline Convertion to CLAP & $45.24 \pm 12.14$ & \\
\hline Mean operative time in minutes & $35-79$ & \\
Range & & \\
\hline Accessability of the appendix & 56 & $77.8 \%$ \\
Accessable & 16 & $22.2 \%$ \\
Difficult & & \\
\hline Post-operative complications & 2 & $2.8 \%$ \\
Ileus & $41.99 \pm 6.53$ & \\
\hline Mean hospital stay in hours & $35-72$ & \\
Range in hours & \multicolumn{2}{|l}{} \\
\hline
\end{tabular}

to its low costs and, the use of conventional laparoscopic equipment. Moreover, surgical glove port has been adopted for several minimal procedures, including cholecystectomies and appendectomies [8,17-20].

Martynov and Lacher [9] stated that the surgical equipments needed to perform SILT in children are very expensive and they added that the use of surgical glove port is not only cheap but allows a wide range of movement of the instruments without collisions". In another study there was significant decrease of the time of surgery between SILT using conventional laparoscopic equipments compared with CLA [21].

In this study, the mean operative time of GSPLA procedure was $45.24 \pm 12.14 \mathrm{~min}$. (ranged from 35 to 79 mints.). The operative time for the first 2 patients was more than 64 minutes due to the early learning curve and because it took long time by the surgical team to get familiar with the technique. Then, the operative time was deceased gradually in the following cases.

\section{Discussion}

It is well known that the surgical management of appendicitis is appendectomy. The first surgeon carried out appendectomy by laparoscopy was Kurt Semm in 1983 [10,11]. Conventional laparoscopic appendectomy (CLA) has been widely applied for the treatment of complicated and uncomplicated appendicitis [3-5].

Beside its role in confirmation of the diagnosis, laparoscopy has less postoperative pain and low doses of analgesics. It enables early activities and food intake and a short hospital stay. Thus, patients can return early to normal activities and also have fewer cosmetic problems after surgery. For these reasons, CLA is one of the most frequently performed emergency operations [12]. According to what documented in the literature by many authors, the procedure SILS has a lot of benefits to the patients as performing more than one procedure by the same approach, good patient compliance regarding post-operative pain and possibility for conversion to the classic multiport laparoscopic procedure [13-15].

In a recent study by Martynov and Lacher, they documented that there are a several shapes of SILT available in the market with curved laparoscopic instruments but, it is costly if compared with glove single port used in the current study and in country with low available resources [9]. This also agreed with Lee., et al. in their study using the same procedure with conventional laparoscopic instruments with low cost [16].

In a randomized controlled trial done by Lee., et al. comparing SILT with CLA they have documented that postoperative results were similar. However, the increased costs for SILT compared to CLA, especially when carried out by costly curved instruments is a limitation of SILT technique. However, the technique used in this study became popular and used by many authors. This may be due

Also, using the home-made surgical glove as a single port for the treatment of AAP in children and adolescents has benefits; it is easy to use and can be simply introduced into the abdominal cavity even in obese children. It permits the laparoscopic instruments to be passed through small incision. In addition, the glove acts as a barrier preventing the contact of the appendix to abdominal wall during retrieval of the appendix with no need for laparoscopic endobag especially low resource countries. The umbilical incision is small; this minimizes postoperative pain and the rate of development of infection or umbilical hernia due to the barrier effect of the glove.

Many commercial SILT have 3 or 4 ports, whereas the glove single port has ports for five instruments at the same time. Moreover, it is very cheap than the other SILT available in the market. The elasticity of the surgical glove single port permits a good range of movements of the instruments with enough triangulation with minimal collision. When additional instruments were needed, a small cut was made in the tip of the gloves port without using a trocar and tied with a previously prepared elastic strip $[9,16]$.

According to the present study, the GSPLA technique has been shown to be not only feasible but also safe and effective, with a short learning curve. A team work between the surgeon and camera man is very important to carry out the technique smoothly and rapidly. Smoke that result from monopolar diathermy somewhat is another problem that may slow the procedure as there is no separate venting channel in cases of GSPLA.

In the current study, all cases were completed laparoscopically using GSPLA except 5 (6.9\%) cases needed insertion of assassinating instrument [ 3 with multiple adhesions and 2 with retrocecal position of the appendix. No case needed conversion to open 
surgery and this agreed with Lee., et al. in their study comparing home-made port with conventional laparoscopic procedure [16]. Pittman-Waller., et al. earlier stated that in their study, a higher conversion rate was present with SILT due to technical difficulties where complicated appendicitis was present in $30 \%$ of their cases [22].

In this study, early mobilization was advised and the majority of patients were usually discharged on the second post-operative day. The mean postoperative hospital stay was ranged from 35 - 72 (Mean of $41.99 \pm 6.53$ Hours).

\section{Limitation of this Study}

The clinical limitation of the present study is its application in only non-complicated appendicitis and the small number of cases. But this may be explained by our initial results with early learning curve to be familiar of this technique. Larger numbers together with long term follow up of cases are needed to support the idea of this technique in the future.

\section{Conclusion}

The glove single-port laparoscopic appendectomy is a new technique which is cheaper than the other SILT devices. According to the results of this study, laparoscopic appendectomy in pediatric age using the home-made glove single port is quite easy to be done for non-complicated appendicitis with short learning curve. This technique provides high flexibility and wide range of movements of laparoscopic instruments.

\section{Acknowledgement}

All authors would like to thank and appreciate Rafik Shalaby, Professor of Pediatric Surgery and innovator of laparoscopic surgery, Al-Azhar University, Cairo, Egypt for his encouragements and support for mastering this technique and meticulous revision of this article.

Funding

None.

\section{Conflict of Interest}

None.

\section{Bibliography}

1. Buicko Jessica L., et al. "Pediatric laparoscopic appendectomy, risk factors, and costs associated with nationwide readmissions". Journal of Surgical Research 215 (2017): 245-249. https://doi.org/ 10.1016/ j.jss.2017.04.005

2. Almaramhy Hamdi Hameed. "Acute appendicitis in young children less than 5 years". Italian Journal of Pediatrics 43.1 (2017): 15. DOI https:// doi.org/ 10.1186/ s13052-0170335-2
3. Sweeney KJ and FBV Keane. "Moving from open to laparoscopic appendicectomy". British Journal of Surgery 90.3 (2003): 257-258. https://doi.org/10.1002/bjs.4070

4. Konstadoulakis Manousos M., et al. "Two-trocar laparoscopic-assisted appendectomy versus conventional laparoscopic appendectomy in patients with acute appendicitis". Journal of Laparoendoscopic and Advanced Surgical Techniques 16.1 (2006): 27-32. https://doi.org/ 10.1089/ lap.2006.16.27

5. Horvath P., et al. "Comparison of clinical outcome of laparoscopic versus open appendectomy for complicated appendicitis". Surgical endoscopy 31.1 (2017): 199-205. https://doi. org/10.1007/s00464-016-4957-z

6. Kim Ji Hoon., et al. "Single-incision laparoscopic appendectomy versus conventional laparoscopic appendectomy". Annals of Surgery 262.6 (2015): 1054-1058. https://doi.org/10.1097/ SLA. 0000000000001064

7. Aly Omar E., et al. "Single incision laparoscopic appendicectomy versus conventional three-port laparoscopic appendicectomy: A systematic review and meta-analysis". International Journal of Surgery 35 (2016): 120-128. https://doi.org/ 10. 1016/ j.ijsu.2016.09.087

8. Binenbaum Steven J., et al. "Single-incision laparoscopic cholecystectomy using a flexible endoscope". Archives of Surgery 144.8 (2009): 734-738. doi:10.1001/archsurg.2009.129

9. Martynov Illya and Martin Lacher. "Homemade Glove Port for Single-Incision Pediatric Endosurgery (SIPES) Appendectomy - How We Do It". European Journal of Pediatric Surgery Reports 6.01 (2018): e56-e58. DOI: 10.1055/s-0038-1667140

10. McBurney CM. "Experience with early operative interference in cases of disease of the vermiform appendix". New York State Journal of Medicine 50 (1889): 676-684. NII Article ID (NAID) 10024137891

11. Semm K. "Endoscopic appendectomy". Endoscopy 15.02 (1983): 59-64. DOI: 10.1055/s-2007-1021466

12. Khan Muhammad Najm., et al. "Laparoscopic versus open appendectomy: the risk of postoperative infectious complications". JSLS: Journal of the Society of Laparoendoscopic Surgeons 11.3 (2007): 363. PMID: 17931520

13. Binet Aurelian., et al. "Laparoscopic one port appendectomy: Evaluation in pediatric surgery". Journal of Pediatric Surgery 53.11 (2018): 2322-2325. https://doi.org/10.1016/ j.jpedsurg.2017.12.018 
14. Oltmann, Sarah C., et al. "Single-incision laparoscopic surgery: feasibility for pediatric appendectomies". Journal of Pediatric Surgery 45.6 (2010): 1208-1212. https://doi.org/10.1016/j. jpedsurg.2010.02.088

15. Lee Seung Eun., et al. "Single port laparoscopic appendectomy in children using glove port and conventional rigid instruments". Annals of Surgical Treatment and Research 86.1 (2014): 35-38. https://doi.org/10.4174/astr.2014.86.1.35

16. Lee Sang Myoung and Go Sung Hwang. "Single-incision laparoscopic appendectomy using homemade glove port at low cost". Journal of Minimal Access Surgery 12.2 (2016): 124. doi: 10.4103/0972-9941.169979

17. Lee Won-Suk, et al. "Single-port laparoscopic appendectomy versus conventional laparoscopic appendectomy: a prospective randomized controlled study". Annals of Surgery 257.2 (2013): 214-218. doi: 10.1097/SLA.0b013e318273bde4

18. Di Saverio, Salomone, et al. "Single-incision laparoscopic appendectomy with a low-cost technique and surgical-glove port: "how to do it" with comparison of the outcomes and costs in a consecutive single-operator series of 45 cases". Journal of the American College of Surgeons 222.3 (2016): e15-e30. DOI: https:// doi.org/10.1016/j.jamcollsurg.2015.11.019

19. Hong Tae Ho., et al. "Transumbilical single-port laparoscopic appendectomy (TUSPLA): scarless intracorporeal appendectomy". Journal of Laparoendoscopic and Advanced Surgical Techniques 19.1 (2009): 75-78. https://doi.org/ 10.1089/ lap.2008.0338

20. Chow Andre., et al. "Single incision laparoscopic surgery for appendicectomy: a retrospective comparative analysis". Surgical Endoscopy 24.10 (2010): 2567-2574. DOI https://doi. org/10.1007/s00464-010-1004-3

21. Lee Jun Suh., et al. "Transumbilical single port laparoscopic appendectomy using basic equipment: a comparison with the three ports method". Journal of the Korean Surgical Society 83.4 (2012): 212-217. https://doi.org/ 10.4174/ jkss.2012.83.4.212

22. Pittman-Waller Virginia A., et al. "Appendicitis: why so complicated? Analysis of 5755 consecutive appendectomies". The American Surgeon; Atlanta 66.6 (2000): 548-554.

\section{Assets from publication with us}

- Prompt Acknowledgement after receiving the article

- Thorough Double blinded peer review

- Rapid Publication

- Issue of Publication Certificate

- High visibility of your Published work

Website: www.actascientific.com/

Submit Article: www.actascientific.com/submission.php Email us: editor@actascientific.com

Contact us: +919182824667 